\title{
Formal Contracts, Relational Contracts, and the Holdup Problem*
}

\author{
Hideshi Itoh ${ }^{\dagger} \quad$ Hodaka Morita ${ }^{\ddagger}$
}

January 26, 2005

*We are grateful to Murali Agastya, Shingo Ishiguro, Shinsuke Kambe, Michihiro Kandori, Kieron Meagher, Bill Schworm, Kunal Sengupta, Noriyuki Yanagawa, and the seminar participants at University of Tokyo Microeconomics Workshop and University of New South Wales for helpful comments. Part of this research was conducted while the first author was visiting Center for Economic Studies (CES), University of Munich, and School of Economics, University of New South Wales. He is grateful to these institutions for their hospitality, as well as to Hitotsubashi University (Kyointo Kaigaihaken Shogakukin and the 21st Century COE program "Dynamics of Knowledge, Corporate System and Innovation") and Japan Society for the Promotion of Science (Japan-Australia Research Cooperative Program), for their financial support.

${ }^{\dagger}$ Graduate School of Commerce and Management, Hitotsubashi University.

${ }^{\ddagger}$ School of Economics, University of New South Wales. 


\begin{abstract}
We study the holdup problem in repeated transaction between a seller and a buyer such that the seller makes relation-specific investments in each period. We show that in situations where formal contracts have no value under spot transaction due to the cooperative nature of investment, writing a simple fixed-price contract can be valuable under repeated transaction: There is a range of parameter values in which a higher investment can be implemented only if a formal price contract is written and combined with a relational contract. We also show that there are cases in which not writing a formal contract but entirely relying on a relational contract increases the total surplus of the buyer and the seller. The key condition is how the investment affects the renegotiation price in general, and the alternative-use value in particular.
\end{abstract}

JEL Classification Numbers: D23, L14, L22, L24.

KEYWORDs: Holdup problem, formal contract, relational contract, cooperative investment, fixed-price contract, relation-specific investment, renegotiation, repeated transaction, long-term relationships. 


\section{Introduction}

Relation-specific investments often cause holdup problems when contracting is incomplete. Suppose as an example that a seller has an opportunity to make an investment, which creates more value inside its relationship to a particular buyer than outside. Relation-specific nature of the investment may result in the buyer's opportunistic behavior. Contracts contingent upon investment-related information could protect the seller, but this is often difficult in reality. Without adequate contractual protection, the seller's anticipation of the opportunistic behavior results in less than the socially optimal level of investment. The holdup problem has played a central role in the economic analysis of organizations and institutions, where many authors proposed various organizational interventions, such as vertical integration (Klein et al., 1978; Williamson, 1985), as remedies to the problem.

In the holdup literature, a fundamental driving force of the inefficiency has been the assumption that contracts contingent upon the nature of relation-specific investment are infeasible, which is a realistic assumption in a wide variety of real-world

bilateral trade. On the other hand, the courts can often verify delivery of the goods by the seller, and hence simple noncontingent contracts based on product delivery are often feasible.

Recently several articles have proposed that such a simple contract could resolve the holdup problem. Edlin and Reichelstein (1996) considered a bilateral trade relationship in which the seller and the buyer can write a simple contract that specifies a fixed trade price and quantity at a future date. The seller then decides how much to invest in a relation-specific asset that lowers the subsequent cost of producing the good. After the investment is made, some state uncertainty, which affects the seller's cost as well as the buyer's valuation, is resolved and observed. The buyer and seller are then free to renegotiate on the contract with exogenously specified bargaining strengths. Edlin and Reichelstein found that a well-designed fixed-price contract can give the seller efficient investment incentives.

Che and Hausch (1999) pointed out that these previous studies were limited by their restriction on the nature of the relation-specific investments; that is, these studies focused on "selfish" investments that benefit the investor (e.g., the seller's invest- 
ment reduces his production costs). Che and Hausch convincingly argued through a number of examples that "cooperative" investments (e.g., the seller's investment improves the buyer's value of the good) were equally important, although cooperative investments had received little attention in the literature. For instance, the famous General Motors-Fisher Body example deals with Fisher Body's decision of whether to build a plant adjacent to General Motors. Such an arrangement involves "selfish" as well as "cooperative" aspect, because it not only lowers shipping costs but also improves supply reliability.

Che and Hausch found very different results for cooperative investments. They considered a bilateral trade relationship similar to the one analyzed by Edlin and Reichelstein. The most important result of Che and Hausch concerns the case in which the parties cannot credibly commit not to renegotiate the contract. They showed that if investments are sufficiently cooperative, then there exists an intermediate range of bargaining shares for which contracting has no value; i.e., contracting offers the parties no advantages over ex post negotiation. In particular, contracting has no value for all parameter range if both investments are purely cooperative (that is, the seller's investment benefits the buyer only, and the buyer's investment benefits the seller only).

We show that this "formal contracting has no value" result for cooperative investments changes drastically under infinitely repeated interaction between the parties. Our most important finding concerns the case in which the discount factor is not high enough so that repeated transaction itself cannot resolve the holdup problem. We show that a formal fixed-price contract, combined with informal agreements sustained by the value of future relationships, can help resolving the holdup problem: A higher investment can be implemented for a wider range of parameter values (e.g., discount factor), with a combination of a formal contract and informal agreements than with informal agreements only. In other words, formal contracting plays a complementary role of relaxing the self-enforceability condition for informal agreements.

In what follows we discuss two fundamental driving forces of our main result. First, we analyze the holdup problem under repeated interaction. Relation-specific investments are often made under long-term relationships. Coase (1988) pointed 
out that A.O. Smith, a large independent manufacturer of automobile frames, had invested in expensive equipments that were highly specific to its main customer such as General Motors for more than fifty years. Also, Coase (2000) found that, prior to the acquisition of Fisher Body by General Motors in 1926, Fisher Body had repeatedly made location-specific investments for General Motors. Regarding Japanese manufacturer-supplier relationships, Asanuma (1989) studied the Japanese automobile and the electric machinery industries and found that long-term relationships were more likely to be observed in the transaction of intermediate products that require higher degree of relation-specific investments. According to Holmström and Roberts (1998, p.83), "Nucor [the most successful steel maker in the United States over the past 20 years] decided to make a single firm, the David J. Joseph Company (DJJ), its sole supplier of scrap. Total dependence on a single supplier would seem to carry significant hold-up risks, but for more than a decade, this relationship has been working smoothly and successfully."

Despite the important connection between relation-specific investments and longterm relationships, to the best of our knowledge there are very few theoretical analyses that have previously addressed the holdup problem under infinitely repeated interaction. ${ }^{1}$ This might be because, due to the "Folk Theorem" type reasoning, the holdup problem could obviously be resolved under infinitely repeated interaction if the discount factor is high enough. In contrast, our main contribution is to show that formal fixed-price contracts can play an important role in mitigating the holdup problem when the discount factor is not high enough so that repeated interaction itself cannot resolve the problem.

Second driving force of our result concerns the effect of relation-specific investment on the alternative-use value. In our general analysis, formal contacting can have a positive value when the investment reduces the renegotiation price, while formal contracting has no value otherwise. And a necessary condition for the renegotiation price being decreasing is that the investment reduces the alternative-use value. Most previous theoretical models in the holdup literature assumed, implicitly

\footnotetext{
${ }^{1}$ Note that while several recent papers introduce dynamic structures into the analysis of the holdup problem (Che and Sákovics, 2004; Gul, 2001; Pitchford and Snyder, 2004), they study repeated offers rather than repeated transaction.
} 
or explicitly, that relation-specific investment increases the value of the asset not only within the relationship but also in alternative uses. However, an equally plausible assumption is that the investment reduces the value of the asset in alternative uses. For example, if a seller locates its plant adjacent to a buyer, the seller ends up increasing the distance from the plant to alternative buyers. That is, location-specific investment decreases the value of the asset in alternative uses. Rajan and Zingales (1998), an important exception in the existing literature, argue that relation-specific investments in a physical asset imply, almost by definition, a reduction in the outside value of the asset. Our contribution here is to demonstrate that this distinction is important when we investigate the value of formal contracting under long-term relationships.

Before closing the section, we relate our work to existing literature. Our analysis of informal agreements builds on a general analysis of "relational contracts" by Levin (2003). Baker et al. (1994) and Schmidt and Schnitzer (1995) study how formal contracting affects the self-enforceability of informal agreements. These three papers do not analyze the holdup problem, and hence in their models there is no renegotiation within each period while intra-period renegotiation and the resulting reneging temptation associated with relation-specific investments are crucial features behind our results. Baker et al. (2001, 2002), Halonen (2002), and Morita (2001) analyze the holdup problem in infinitely repeated transaction. Their focus is quite different from ours, however. Baker et al. (2001, 2002) and Halonen (2002) study how asset ownership affects the self-enforceability of relational contracts, and the focus of Morita (2001) is the role of partial ownership in resolving the holdup problem under repeated interaction. None of them captures the idea that formal contracts can play an important role in reducing reneging temptations under repeated transaction, nor identifies the distinction of whether the alternative-use value is increasing or decreasing in investment as an important factor to determine the value of formal contracting. $^{2}$

\footnotetext{
${ }^{2}$ Although Baker et al. (2001, 2002) employ a holdup model different from ours, integration in their model and formal contracting in our model play a similar role of eliminating ex post renegotiation opportunities. We will further elaborate the difference between their papers and ours in section 5, by introducing asset ownership into our model.
} 
The rest of the paper is organized as follows: Section 2 analyzes a simple example in which there are two levels of investment to illustrate our main result and intuition behind it. Section 3 presents our general model of repeated transaction between a seller and a buyer, in which there are $n+1$ possible levels of investment. Section 4 analyzes the model and finds, among other things, that although investment is purely cooperative, there is a range of parameter values under which the buyer is strictly better off by offering a formal contract. Section 5 first discusses the robustness of our result under other forms of formal contracts, and then extends our analysis to distinguish between vertical integration and nonintegration in order to show that writing a formal price contract without integration can still be valuable. Section 6 concludes, with some discussion of relevant empirical literature.

\section{Example}

Setting We can illustrate our main result and intuition behind it by a simple example. There is a seller and a buyer. In each period, the seller can produce at most one unit of a product, and the buyer purchases at most one unit of the product. In each period the seller has an opportunity to make an investment. The seller chooses either no investment (0) or investment (1). The cost for the investment is $a>0$.

The investment does not affect the seller's production cost, which is normalized to zero, but influences the value of the product for the buyer as well as the alternativeuse value. That is, the investment is purely cooperative. Let $v_{i}$ be the value for the buyer and $m_{i}$ the alternative-use value if investment is $i=0,1$. We assume $\Delta_{v} \equiv v_{1}-v_{0}>0$. Most previous theoretical models in the holdup literature assume, implicitly or explicitly, that $\Delta_{m} \equiv m_{1}-m_{0} \geq 0$ : Relation-specific investments increase alternative-use values (at least weakly) as well. However, we believe that $m_{1}<m_{0}$ is equally plausible. For example, suppose that investment 0 represents a general-purpose investment while 1 represents a relation-specific investment. If the seller makes the general-purpose investment, he can produce the general product that has value $m_{0}$ for alternative users. If the seller makes the specific investment, he can produce the product that is customized to the buyer. And if an alternative 
user purchases the specific product, the user must incur an adjustment cost $c>0$ in order to convert it to the general product, and hence the effective value of the specific product for the alternative user is $m_{0}-c$, which is smaller than $m_{0} \cdot{ }^{3}$ Alternatively, suppose that the seller chooses two kinds of investments, relation-specific investment (zero or one unit) that only increases the value for the buyer, and general-purpose investment (zero or one unit) that only increases the alternative-use value. And suppose further that because of various resource constraints, the seller can invest at most one unit of investment. This interpretation of the model corresponds to the case $m_{1}<m_{0} \cdot{ }^{4}$

We thus do not assume $\Delta_{m} \geq 0$ in our analysis but distinguish between $\Delta_{m} \geq 0$ case and $\Delta_{m}<0$ case. We assume (i) $\Delta_{v}>a>\Delta_{m}$; and (ii) $v_{0} \geq \max \left\{m_{1}, m_{0}\right\}$. These two assumptions imply that it is efficient for the seller to invest and trade with the buyer, but the investment cannot be realized under spot transaction.

Each period starts with the buyer's decision to offer a price contract. We make a standard assumption that all the relevant variables are observable but unverifiable to both the seller and the buyer while delivery and transfer are verifiable, and hence a simple price contract can be written and enforced. The buyer's offer is a take-it-orleave-it offer, and the price contract can be a formal contract, an informal agreement, or a combination of these two. Then, if the price contract contains a formal contract, the seller decides whether or not to sign it. Second, the seller chooses whether or not to invest. Third, the buyer and the seller engage in renegotiation, in which the buyer makes a take-it-or-leave-it price offer to purchase a product from the seller. Finally, the seller produces a product and sells it to the buyer or in the outside market.

Spot transaction We first analyze the benchmark case of spot transaction where the seller and the buyer meet only once or do not use history-dependent strategies. We solve for subgame perfect equilibria of the stage game. The buyer's renegotiation price offer is $p_{i}=m_{i}$ if investment is $i=0,1$. Since $m_{0}-\left(m_{1}-a\right)=-\Delta_{m}+a>0$, the seller then chooses not to invest (underinvestment) and hence the holdup problem

\footnotetext{
${ }^{3}$ See also Rajan and Zingales (1998).

${ }^{4}$ See Cai (2003) who studies such a multi-dimensional investment model in which increasing relation-specific investment reduces general-purpose investment and hence reduces the outside value.
} 
arises.

Formal contracts do not help under spot transaction. Consider a simple fixedprice contract such as "pay price $p$ for the delivery of the product." It is enforced with a specific performance damage clause, which is a standard legal breach remedy often applied in practice: When one party sues for specific performance, the court orders the second party to perform exactly what the contract specifies. Such a contract can resolve the holdup problem if the investment is purely "selfish" as in Edlin and Reichelstein (1996). However, when investment is purely "cooperative" as in our model, the seller chooses not to invest in order to save the investment cost $a$, and hence underinvestment persists. ${ }^{5}$ Che and Hausch (1999) in fact showed, in a general setup, that if the parties cannot commit themselves not to renegotiate, they cannot do better by writing a formal contract, along with any communication mechanism, than no contract.

Repeated transaction without a formal contract We now show that this result for spot transaction changes dramatically under repeated transaction. We consider infinitely repeated interaction with perfect monitoring between the seller and the buyer with the common discount factor $\delta \in(0,1)$, and solve for subgame perfect equilibria of the infinitely repeated game that can implement the efficient outcome (investment by the seller). We focus on trigger-strategy equilibria, in which after either party reneges, both the seller and the buyer follow the static equilibrium strategies under spot transaction forever from the next period on. We assume without loss of generality that they do not write a formal contract under the static equilibrium.

Consider the following strategies under which the buyer does not offer a formal contract. At the beginning of each period, the buyer promises to pay $\bar{b}=m_{0}+a$ conditional on the seller's investment. And the buyer actually pays $\bar{b}$ if the seller invests. If the seller chooses no investment, the buyer offers $p_{0}=m_{0}$ at the renegotiation stage in the same period, and then reverts to the static equilibrium strategy from the next period on. The seller chooses to invest if the buyer actually paid $\bar{b}$ in

\footnotetext{
${ }^{5}$ Note that the price contract cannot be contingent on investment that is unverifiable.
} 
the previous periods. Otherwise, he continues to choose no investment forever.

If the seller believes that the buyer follows the strategy given above, then investment results in payoff $\bar{b}-a=m_{0}$ in each period, while no investment yields payoff $p_{0}=m_{0}$. The seller thus has no incentive to deviate, and chooses to invest. However, the buyer may have an incentive to cheat. Suppose the seller invests in a given period. The buyer will be better off in that period by deviating from paying $\bar{b}$ and instead offering $p_{1}=m_{1}$, which the seller will accept. The buyer's reneging temptation is thus $\bar{b}-m_{1}=a-\Delta_{m}>0$. Her future loss from this deviation is given by

$$
\frac{\delta}{1-\delta}\left[\left(v_{1}-\bar{b}\right)-\left(v_{0}-m_{0}\right)\right]=\frac{\delta}{1-\delta}\left(\Delta_{v}-a\right) .
$$

The buyer honors the promise if and only if

$$
a-\Delta_{m} \leq \frac{\delta}{1-\delta}\left(\Delta_{v}-a\right)
$$

that is, if the reneging temptation does not exceed the future loss.

Repeated transaction with a formal contract Next, suppose that in each period the buyer offers a formal fixed-price contract. And we allow the buyer to combine the formal contract with an informal promise. We thus consider the following strategies. At the beginning of each period, the buyer writes a formal price contract $p$ to be paid for delivery of the product, and in addition, promises to pay a bonus $b$ if the seller invests. If the seller does not invest, she will revert to the static equilibrium strategy from the next period on. The seller chooses to invest if the buyer actually offered contract $p$ and paid $b$ in the previous periods. Otherwise, he continues to choose no investment forever.

The important difference from the no formal contract scenario concerns what happens when the buyer reneges on the promised bonus $b$ after the investment being made by the seller, and what happens when the seller does not invest. In both cases, although the buyer does not pay the bonus $b$, she is forced to pay $p$ by the specific performance damage clause, and the buyer and the seller cannot agree on a renegotiation price because at least one party must prefer the formal price $p$. Keeping this difference in mind, we derive the conditions for the efficient outcome to be implemented. 
If the seller believes that the buyer follows the strategy given above, then investment results in payoff $p+b-a$ in each period, while no investment yields payoff $p$ in the current period, and $m_{0}$ from the next period on. The seller thus chooses to invest if his reneging temptation $p-(p+b-a)=a-b$ is at most as high as the future loss:

$$
a-b \leq \frac{\delta}{1-\delta}\left(p+b-a-m_{0}\right)
$$

Suppose next that the seller invests in a given period. The buyer's reneging temptation is $p+b-p=b$. Her future loss from cheating is given by

$$
\frac{\delta}{1-\delta}\left[\left(v_{1}-p-b\right)-\left(v_{0}-m_{0}\right)\right]=\frac{\delta}{1-\delta}\left(\Delta_{v}-p-b+m_{0}\right) .
$$

The buyer thus honors the promise if and only if

$$
b \leq \frac{\delta}{1-\delta}\left(\Delta_{v}-p-b+m_{0}\right)
$$

Summing inequalities (2) and (3) yields a necessary condition for the efficient outcome to be implemented by a combination of a formal contract and an informal promise:

$$
a \leq \frac{\delta}{1-\delta}\left(\Delta_{v}-a\right)
$$

Conversely, if (4) holds, then the buyer can find a self-enforcing contract $(p, b)$ that implements the efficient outcome. The best combination for the buyer is to leave no rent to the seller, $(p, b)$ satisfying $p+b=m_{0}+a$. Substituting this into (2) yields $b \geq a$, and hence $(p, b)=\left(m_{0}, a\right)$ is one best combination for the buyer: The seller chooses to invest without any rent, because the informal bonus contingent upon investment just covers the investment cost $a$.

Comparison We now compare the result under no formal contract with that under a fixed-price contract. Since the buyer can extract all the surplus if an efficient equilibrium exists, the comparison is in terms of the condition for its existence, that is, between (1) and (4). First suppose $\Delta_{m}<0$. Then (1) implies (4) but the reverse is not true. This implies that the buyer is never worse off by writing an appropriate formal contract, and that, although investment is purely cooperative and hence writing a formal contract does not help at all under spot transaction, there 
is a range of parameter values under which the buyer is strictly better off by offering a formal contract. That is, under a certain range of parameter values, the buyer cannot induce the seller to invest without a well-designed formal price contract.

The intuition here goes as follows. In order to induce the seller to invest, the buyer offers an informal but self-enforcing pay contingent on the seller's investment. This role is played by $b$ in either case. The difference is in the reneging temptation. Since all the surplus goes to the buyer, we can restrict our attention to the buyer's reneging temptation. When no formal contract is written, the buyer can hold the seller up by not paying $\bar{b}=m_{0}+a$ and instead offering a renegotiation price $m_{1}=m_{0}+\Delta_{m}$. The buyer's reneging temptation here is $\bar{b}-m_{1}=a-\Delta_{m}$. On the other hand, when a formal price contract $p=m_{0}$ is written, the buyer cannot renegotiate the price below this level to $m_{1}=m_{0}+\Delta_{m}$ (recall that we consider $\Delta_{m}<0$ case here). This means that the buyer can effectively reduce her reneging temptation from $a-\Delta_{m}$ to $a$ by writing the formal fixed-price contract.

Can the self-enforceability of the contract $(p, b)$ be enhanced by further reducing the buyer's reneging temptation from $a$ ? The answer is no, and the logic is as follows: Suppose that the buyer reduces $b$ from $a$ to $a-\epsilon$, which change decreases her reneging temptation by $\epsilon$. However, the left-hand side of (2) is now positive $\epsilon$, and hence the buyer must give per period rent $\epsilon(1-\delta) / \delta$ to the seller to prevent the seller's temptation of no investment. This in turn means that the present discounted value of the buyer's future loss from reneging (the right-hand side of (3)) must also be reduced by $\epsilon$. The result is that the self-enforceability of the contract cannot be enhanced by reducing the buyer's reneging temptation from $a$.

Next suppose $\Delta_{m} \geq 0$. In this case we find that the buyer is never better off by writing a formal contract, and if $\Delta_{m}>0$, there is a range of parameter values under which the buyer is strictly worse off by offering a formal price contract. To see why, suppose that the buyer offers a formal fixed-price contract. As shown above, the best combination for the buyer is $(p, b)$ satisfying $p+b=m_{0}+a$ and $b \geq a$, and hence the buyer's reneging temptation is at least $a$. On the other hand, when no formal contract is written, as shown above the buyer's reneging temptation is $a-\Delta_{m}$, which is less than $a$ given $\Delta_{m}>0$. 
In the subsequent sections, we show the optimality of writing a formal contract in repeated transaction more generally. We show when combining a formal contract with an informal agreement helps, and when an informal promise is sufficient.

\section{Model}

We consider repeated transaction between an upstream party (seller) and a downstream party (buyer). In each period, the seller chooses an investment level $a \in A$ by incurring private cost $d(a)$. We assume that there are $n+1$ possible investment levels $a_{0}, a_{1}, \ldots, a_{n}$ that are measured in terms of the investment costs, and hence $d\left(a_{i}\right)=a_{i}$, and we assume $0 \leq a_{0}<a_{1}<\cdots<a_{n}$.

The seller's investment affects the value of the seller's product for the buyer as well as for the alternative-use value of the product. When the seller's investment is $a_{i}$, let $v_{i}$ be the value for the buyer and $m_{i}$ for the alternative-use value which we assume for simplicity is also equal to the price the seller can sell to an alternative user. The buyer's payoff is zero when the seller does not sell the product to her. For simplicity, we assume that at most one unit of the product is traded, and the production cost is normalized to zero. We assume $v_{i}$ is strictly increasing in $i, v_{0} \geq \max _{i} m_{i}$, and $v_{i}>a_{i}$ for all $i$, so that it is always efficient for the seller and the buyer to trade. Denote the efficient investment by $a^{*}: a^{*}=a_{j}$ where $j=\arg \max _{i}\left(v_{i}-a_{i}\right)$. We assume $a^{*}$ is unique and $a^{*}>a_{0}$.

The alternative-use value $m_{i}$ may be increasing or decreasing (can be nonmonotonic as well). We however follow the holdup literature by assuming that investment affects $v_{i}$ at least as much as $m_{i}$ at margins:

$$
v_{i}-v_{i-1} \geq m_{i}-m_{i-1} \quad \text { for } i=1, \ldots, n .
$$

We assume that $a_{i}, v_{i}, m_{i}$ are observable to both parties but unverifiable, while delivery of the product and transfer payments are verifiable, and hence a fixed-price contract is feasible and enforced with a specific performance damage clause.

In each period, the timing goes as follows. First, the seller and the buyer may sign a contract. Second, the seller chooses investment. Third, the seller and the buyer (re)negotiate a price. We assume that the parties cannot commit themselves 
not to renegotiate, and the renegotiation price is determined by the generalized Nash bargaining solution. Let $\alpha \in[0,1)$ be the seller's share of the gain from trade, and hence the buyer's share is $1-\alpha$. Fourth, the seller produces and sells the product to the buyer at the agreed price or in the outside market.

\section{Analysis}

\subsection{Spot Transaction}

When the seller and the buyer meet only once, or they do not use history dependent strategies, the standard holdup problem can arise. Suppose that no formal price contract is written at the beginning. Since trade is always efficient, the seller and the buyer, after the seller makes investment, decide to trade and negotiate the price. When the seller chooses $a_{i}$, the gain from trade is $v_{i}-m_{i}$, and hence the renegotiation price $p_{i}$ satisfies

$$
p_{i}=m_{i}+\alpha\left(v_{i}-m_{i}\right)=\alpha v_{i}+(1-\alpha) m_{i} .
$$

The seller's payoff is thus

$$
p_{i}-a_{i}=\alpha v_{i}+(1-\alpha) m_{i}-a_{i} .
$$

The seller chooses the investment that maximizes $p_{i}-a_{i}$. Let $a^{o}$ be the optimal investment under spot transaction: $a^{o}=a_{j}$ where $j=\arg \max _{i}\left(p_{i}-a_{i}\right)$.

In this setup it is easy to show that the seller does not overinvest.

Proposition 1 If no formal price contract is written at the beginning, the seller does not overinvest under spot transaction: $a^{*} \geq a^{o}$.

Proof Let $a^{*}=a_{j}$ and $a^{o}=a_{i}$, and suppose instead $a_{j}<a_{i}$. Since $a_{j}$ is uniquely efficient, $v_{j}-a_{j}>v_{i}-a_{i}$, or

$$
a_{i}-a_{j}>v_{i}-v_{j}
$$

holds. On the other hand, since $a_{i}$ is optimal under spot transaction, $p_{i}-a_{i} \geq p_{j}-a_{j}$ holds. Then, by $\alpha<1, a_{i}>a_{j}$, and (5),

$$
a_{i}-a_{j} \leq \alpha\left(v_{i}-v_{j}\right)+(1-\alpha)\left(m_{i}-m_{j}\right) \leq v_{i}-v_{j}
$$


must hold, which is a contradiction.

Q.E.D.

Since the seller cannot reap all the returns from investment, his optimal investment choice is at most $a^{*}$. To make the analysis interesting, we hereafter assume $a^{*}>a^{o}$ : If $a^{*}=a_{j}$, there exists $i<j$ such that

$$
a_{j}-a_{i}>\alpha\left(v_{j}-v_{i}\right)+(1-\alpha)\left(m_{j}-m_{i}\right) .
$$

When $a^{o}=a_{i}$, define the seller's payoff, the buyer's payoff, and the joint surplus, respectively, as follows:

$$
\pi_{S}^{o}=w+p_{i}-a_{i}, \quad \pi_{B}^{o}=v_{i}-w-p_{i}, \quad \pi^{o}=\pi_{S}^{o}+\pi_{B}^{o}=v_{i}-a_{i}
$$

where $w$ is a fixed transfer paid from the buyer to the seller at the beginning of the period (negative $w$ implies payment from the seller to the buyer), that serves the distribution purpose only.

\subsection{Relational Contract}

We now consider the case in which the seller and the buyer engage in infinitely repeated transaction, with the common discount factor $\delta$. Suppose that at the beginning of each period, the seller and the buyer agree on an informal compensation plan, with the seller's promising investment $a_{j}$. In this subsection, we assume no formal price contract is written. The effects of writing a formal price contract is analyzed in the next subsection. The informal compensation plan consists of $\left(w, b_{0}, \ldots, b_{n}\right)$, where $w$ is paid from the buyer to the seller at the beginning of each period, and $b_{i}$ is a price paid by the buyer when the seller's investment is $a_{i}\left(b_{i}\right.$ may be negative, in which case it is a penalty paid by the seller). A relational contract is a complete plan for the relationship, describing for every period and history the compensation plan and the seller's investment. We study trigger-strategy equilibria in which if either reneges on the payment or investment, then they renegotiate to determine the price and from the next period on, they revert to spot transaction. The optimal contract is the one that maximizes the joint surplus.

We focus on stationary contracts under which in every period the parties agree on the same compensation plan and the seller chooses the same investment on the equilibrium path. Our focus on stationary contracts is without loss of generality, due to 
Levin (2003): If an optimal contract exists, there are optimal stationary contracts. ${ }^{6}$ And a similar logic can be applied to show that we can further restrict our attention to contracts that provide the seller's investment incentives with discretionary payments alone.

Since a relational contract is in general contingent on the seller's investment that is observable but unverifiable, it must satisfy conditions under which it is neither party's interest to renege on the contract: it must be self-enforcing, i.e., a subgame perfect equilibrium of the repeated game. We obtain conditions under which there exists a self-enforcing (stationary) relational contract that implements a given investment $a_{j}$ attaining a higher total surplus than $a^{o}$.

First, the seller's incentive compatibility constraints are given as follows.

$$
b_{j}-b_{i} \geq a_{j}-a_{i} \quad \text { for all } i \neq j
$$

Note that future payoffs do not appear in the constraints.

Second, if the seller chooses $a_{i}$ and the buyer does not pay the discretionary price $b_{i}$, then there is renegotiation and the price to be paid is $p_{i}=\alpha v_{i}+(1-\alpha) m_{i}$. The reneging temptation of the buyer is thus $b_{i}-p_{i}$. She will then lose her future per period gain $v_{j}-w-b_{j}-\pi_{B}^{o}$. The buyer therefore honors the agreement if and only if

$$
b_{i}-p_{i} \leq \frac{\delta}{1-\delta}\left(v_{j}-w-b_{j}-\pi_{B}^{o}\right)
$$

holds for all $i$. The equivalent condition is given as follows.

$$
\max _{i}\left(b_{i}-p_{i}\right) \leq \frac{\delta}{1-\delta}\left(v_{j}-w-b_{j}-\pi_{B}^{o}\right)
$$

Third, if the seller chooses $a_{i}$ and does not pay the penalty $-b_{i}$, he is instead paid the renegotiation price $p_{i}$. The seller's reneging temptation is hence $-\left(b_{i}-p_{i}\right)$. His future per period loss is $w+b_{j}-a_{j}-\pi_{S}^{o}$. The seller therefore honors the agreement if and only if

$$
-\left(b_{i}-p_{i}\right) \leq \frac{\delta}{1-\delta}\left(w+b_{j}-a_{j}-\pi_{S}^{o}\right)
$$

\footnotetext{
${ }^{6}$ Although Levin (2003) does not analyze a case where the parties engage in renegotiation in each period, it is straightforward to generalize his result to such a situation.
} 
holds for all $i$. This condition is equivalent to

$$
-\min _{i}\left(b_{i}-p_{i}\right) \leq \frac{\delta}{1-\delta}\left(w+b_{j}-a_{j}-\pi_{S}^{o}\right) .
$$

Combining (7) and (8) yields a single necessary condition:

$$
\max _{i}\left(b_{i}-p_{i}\right)-\min _{i}\left(b_{i}-p_{i}\right) \leq \frac{\delta}{1-\delta}\left(\pi_{j}-\pi^{o}\right)
$$

where $\pi_{j}=v_{j}-a_{j}$ is the total surplus under investment $a_{j}$. And (IC) and (9) are also sufficient for investment $a_{j}$ to be implemented: One can find an appropriate $w$ such that $(7),(8)$, and the parties' participation constraints are satisfied.

Now suppose $a^{o}=a_{k}$, and $a_{j}$ can be implemented: There exists a compensation plan $\left(b_{0}, \ldots, b_{n}\right)$ satisfying (IC) and (9). Since $b_{j}-p_{j} \leq \max _{i}\left(b_{i}-p_{i}\right)$ and $b_{k}-p_{k} \geq$ $\min _{i}\left(b_{i}-p_{i}\right)$,

$$
\max _{i}\left(b_{i}-p_{i}\right)-\min _{i}\left(b_{i}-p_{i}\right) \geq\left(b_{j}-p_{j}\right)-\left(b_{k}-p_{k}\right)
$$

holds. Therefore by (IC) and (9), the following condition follows.

$$
\left(a_{j}-a_{k}\right)-\left(p_{j}-p_{k}\right) \leq \frac{\delta}{1-\delta}\left(\pi_{j}-\pi^{o}\right)
$$

The next proposition shows that condition (DE-NC) is necessary and sufficient for the implementation of $a_{j}$.

Proposition 2 Suppose no formal price contract is written and $a^{o}=a_{k}$. Investment $a_{j}$ satisfying $\pi_{j}>\pi_{k}$ can be implemented by a relational contract if and only if (DENC) holds.

Proof We only need to prove the sufficiency part. Supposing (DE-NC), we construct a compensation plan that satisfies (IC) and (9). Let $b_{k}$ given arbitrarily and define $b_{0}, \ldots, b_{n}$ as follows: ${ }^{7}$

$$
\begin{aligned}
& b_{j}-b_{k}=a_{j}-a_{k} \\
& b_{i}-b_{k}=p_{i}-p_{k}, \quad \text { for all } i \neq j
\end{aligned}
$$

\footnotetext{
${ }^{7}$ The fixed payment $w$ is only used to guarantee that (7), (8), and the participation constraints are satisfied.
} 
By definition, (IC) is satisfied for $i=k$. And for $i \neq k$, (IC) holds because

$$
\begin{aligned}
\left(b_{j}-b_{i}\right)-\left(a_{j}-a_{i}\right) & =\left(b_{j}-b_{k}\right)-\left(a_{j}-a_{k}\right)+\left(b_{k}-b_{i}\right)-\left(a_{k}-a_{i}\right) \\
& =\left(b_{k}-b_{i}\right)-\left(a_{k}-a_{i}\right) \\
& =\left(p_{k}-p_{i}\right)-\left(a_{k}-a_{i}\right) \geq 0
\end{aligned}
$$

where the second and the third equalities follow from the definition of $b_{i}$ and $b_{k}$, and the inequality holds because $a^{o}=a_{k}$.

We next show $\max _{i}\left(b_{i}-p_{i}\right)=b_{j}-p_{j}$. First, for $i=k$,

$$
\begin{aligned}
\left(b_{j}-p_{j}\right)-\left(b_{k}-p_{k}\right) & =\left(p_{k}-p_{j}\right)-\left(b_{k}-b_{j}\right) \\
& =\left(p_{k}-p_{j}\right)-\left(a_{k}-a_{j}\right) \geq 0
\end{aligned}
$$

by the definition of $b_{j}$ and $b_{k}$, and $a^{o}=a_{k}$. Next, by the definition of $b_{i}$ and $b_{k}$, for $i \neq j, k$,

$$
\left(b_{i}-p_{i}\right)-\left(b_{k}-p_{k}\right)=\left(b_{i}-b_{k}\right)-\left(p_{i}-p_{k}\right)=0
$$

and hence $\left(b_{j}-p_{j}\right)-\left(b_{i}-p_{i}\right)=\left(b_{j}-p_{j}\right)-\left(b_{k}-p_{k}\right) \geq 0$.

Furthermore, (11) yields $\min _{i}\left(b_{i}-p_{i}\right)=b_{k}-p_{k}$. We therefore obtain

$$
\begin{aligned}
\max _{i}\left(b_{i}-p_{i}\right)-\min _{i}\left(b_{i}-p_{i}\right) & =\left(b_{j}-p_{j}\right)-\left(b_{k}-p_{k}\right) \\
& =\left(a_{j}-a_{k}\right)-\left(p_{j}-p_{k}\right)
\end{aligned}
$$

(9) now follows from (DE-NC).

Q.E.D.

Condition (DE-NC) is the necessary and sufficient condition for $a_{j}$ to be implemented without any formal price contract under repeated transaction. Note that the condition only depends on the parameters under the investment to be implemented $\left(a_{j}\right)$ and that most preferred by the seller under spot transaction $\left(a^{o}=a_{k}\right)$. Intuitively, the seller's incentive compatibility constraints are binding at $a_{i}=a_{k}$, and the buyer must pay the seller sufficiently higher $\left(a_{j}-a_{k}\right)$ for investment $a_{j}$ than for $a_{k}$. However, the higher pay for $a_{j}$ results in the reneging temptations of both parties. The buyer faces the temptation not to pay bonus $b_{j}$ but to pay the renegotiation price $p_{j}$. The seller faces the temptation to choose $a_{k}$, and not to pay penalty $-b_{k}$ 
but to receive $p_{k}$. The total reneging temptation is thus equal to the left-hand side of (DE-NC), which must be at most as large as the total future loss.

Note that the right-hand side of (9) or (DE-NC) does not depend on the compensation plan. There is hence no compensation plan that makes the total reneging temptation given in the left-hand side of (9) smaller than the left-hand side of (DE-NC). Therefore, the compensation plan that satisfies (10) in the proof of the proposition minimizes the left-hand side of (9), and in this sense, it is an optimal contract implementing a given investment $a_{j}$.

\subsection{Formal Price Contract}

Next suppose that at the beginning of each period, the buyer and the seller sign a formal fixed-price contract enforced with a specific performance damage clause. Since in our model the investment is purely cooperative, fixed-price contracts perform at most as well as no contract under spot transaction. To see this, note that no renegotiation occurs since trade is always efficient. And since the seller is sure to receive the contractually specified fixed-price, he has an incentive to save the investment cost most by choosing $a_{0}$. The seller can in fact save the cost since the court cannot observe this deviation. ${ }^{8}$ The outcome is worse than the no contract case where although the seller underinvests, he may choose investment higher than $a_{0} \cdot 9$

Under repeated transaction, the story is different. We again focus on stationary contracts that provide the seller's incentives with payments only. Let $p$ be the price specified in the formal fixed-price contract at the beginning of each period. In addition, the parties can agree on a compensation plan $\left(w, b_{0}, \ldots, b_{n}\right)$ as well. Note that if either party reneges on payments, no renegotiation arises because price $p$ is enforced. From the next period on, the parities revert to spot transaction in which we assume no formal price contract is written since writing a formal contract is weakly dominated. We derive conditions for the self-enforcing relational contract implementing a given investment $a_{j}$ to exist.

\footnotetext{
${ }^{8}$ We later examine other forms of formal contracts.

${ }^{9}$ It is easy to show that the total surplus under $a^{o}=a_{k}$ is at least as large as that under $a_{0}$.
} 
The seller's incentive compatibility constraints do not change from those under no formal price contract, and are given by (IC). The buyer honors the agreement if and only if

$$
b_{i} \leq \frac{\delta}{1-\delta}\left(v_{j}-p-w-b_{j}-\pi_{B}^{o}\right)
$$

for all $i$, which is equivalent to

$$
\max _{i} b_{i} \leq \frac{\delta}{1-\delta}\left(v_{j}-p-w-b_{j}-\pi_{B}^{o}\right)
$$

Note that after reneging, the seller and the buyer do not agree to renegotiate the fixed price $p$. Similarly, the seller honors the agreement if and only if

$$
-b_{i} \leq \frac{\delta}{1-\delta}\left(p+w+b_{j}-a_{j}-\pi_{S}^{o}\right)
$$

for all $i$, which is equivalent to

$$
-\min _{i} b_{i} \leq \frac{\delta}{1-\delta}\left(p+w+b_{j}-a_{j}-\pi_{S}^{o}\right) .
$$

Combining these conditions yields

$$
\max _{i} b_{i}-\min _{i} b_{i} \leq \frac{\delta}{1-\delta}\left(\pi_{j}-\pi^{o}\right)
$$

By further combining (IC) and (12), we obtain the following result.

Proposition 3 Investment $a_{j}$ satisfying $\pi_{j}>\pi^{o}$ can be implemented by a combination of a formal price contract and a relational contract if and only if the following condition holds.

$$
a_{j}-a_{0} \leq \frac{\delta}{1-\delta}\left(\pi_{j}-\pi^{o}\right)
$$

Proof The necessity part follows from $\max _{i} b_{i}-\min _{i} b_{i} \geq b_{j}-b_{0}$ and (IC) for $i=0$. To prove the sufficiency part, suppose (DE-FP) holds. And for an arbitrary $b_{0}$ define $b_{1}, \ldots, b_{n}$ by $b_{j}-b_{0}=a_{j}-a_{0}$ and $b_{i}=b_{0}$ for all $i>0$ and $i \neq j$. Since $b_{j}-a_{j}=b_{0}-a_{0}>b_{i}-a_{i}$ for all $i>0$ and $i \neq j$, (IC) is satisfied. And (12) follows from (DE-FP) because

$$
\max _{i} b_{i}-\min _{i} b_{i}=b_{j}-b_{0}=a_{j}-a_{0}
$$

Q.E.D. 


\subsection{Comparison}

We can analyze the value of writing a formal fixed-price contract in repeated transaction by comparing two conditions, (DE-NC) for the case of no formal price contract, and (DE-FP) for the case of writing a formal price contract.

The conditions differ only in terms of the reneging temptation given in the lefthand side, and the reneging temptation is different in two respects. First, the seller's optimal investment under spot transaction may be different. It is always $a_{0}$ under a formal fixed-price contract, while the optimal investment under no formal contract, $a^{o}$, may be higher than $a_{0}$. Under no formal price contract the seller may choose an investment higher than the least costly level, because the investment affects the renegotiation price. When no formal contract is written, there is renegotiation, and the renegotiation price depends on the seller's share $(\alpha)$, the value for the buyer $\left(v_{i}\right)$, and the alternative-use value $\left(m_{i}\right)$. Since the value for the buyer is increasing in investment, it provides the seller with an incentive to choose higher investment if the seller's share is positive. Furthermore, if the alternative-use value increases with investment, it provides an additional incentive to increase investment, although the effect is not as large as that of the value for the buyer because of (5). And even if the alternative-use value is decreasing, the marginal benefit of investment for the buyer captured by the seller may be so large that the seller is induced to choose $a^{o}>a_{0}$.

Second, the renegotiation price also affects the reneging temptation when no formal contract is written, while the renegotiation price has no effect on the reneging temptation when a fixed-price contract is signed, since the parties cannot reach an agreement.

The following comparative result is now immediate.

Proposition 4 Suppose $a^{o}=a_{k}$ and consider the implementation of $a_{j}$ satisfying $\pi_{j}>\pi^{o}$.

(a) Suppose $\left(a_{k}-a_{0}\right)+\left(p_{j}-p_{k}\right)<0$ holds. If $a_{j}$ can be implemented under repeated transaction without any formal contract, the same investment can be implemented under repeated transaction with an appropriate formal fixedprice contract. And there is a range of parameter values in which $a_{j}$ can be 
implemented only if a formal price contract is written.

(b) Suppose $\left(a_{k}-a_{0}\right)+\left(p_{j}-p_{k}\right)>0$ holds. If $a_{j}$ can be implemented under repeated transaction with a formal fixed-price contract, the same investment can be implemented under repeated transaction without any formal price contract. And there is a range of parameter values in which $a_{j}$ can be implemented only if no formal price contract is written.

Proposition 4 (a) shows that in contrast to a well-known result in the case of spot transaction that "formal contracting has no value," a simple fixed-price contract, combined with an informal compensation plan, can help mitigate the holdup problem under repeated transaction. Condition $\left(a_{k}-a_{0}\right)+\left(p_{j}-p_{k}\right)<0$ reflects two kinds of differences in the reneging temptation explained above. To better understand the condition, we first suppose $a^{o}=a_{k}=a_{0}$ : Under spot transaction, the seller faces no incentive to invest higher than the least costly investment. This holds if

$$
\alpha\left(v_{i}-v_{0}\right)+(1-\alpha)\left(m_{i}-m_{0}\right)<a_{i}-a_{0}, \quad \text { for all } i>0
$$

Then the condition is equivalent to $p_{j}<p_{0}$. By eliminating the effect of the renegotiation price on the reneging temptation, a well-designed formal price contract reduces the reneging temptation from $\left(a_{j}-a_{0}\right)-\left(p_{j}-p_{0}\right)$ to $a_{j}-a_{0}$. Therefore, there is a range of parameter values in which (DE-FP) holds while (DE-NC) does not.

Since the renegotiation price is determined by the generalized Nash bargaining solution, $p_{j}-p_{0}=\alpha\left(v_{j}-v_{0}\right)+(1-\alpha)\left(m_{j}-m_{0}\right)$. A necessary condition for $p_{j}-p_{0}<0$ is thus $m_{j}<m_{0}$ : The alternative-use value must be lower under the higher investment $a_{j}$ than under $a_{0}$. We have already argued in the previous sections that this is plausible under some settings. Under repeated transaction, this marginal change of the alternative-use value brings a new negative effect of raising the total reneging temptation under no formal contract. The fixed-price contract can eliminate this negative "market incentive" and hence can be valuable.

On the other hand, Proposition 4 (b) shows that if the marginal effect of investment on the alternative-use value is positive, eliminating such a positive "market 
incentive" by writing a fixed-price contract may reduce the total surplus under repeated transaction. Note that the result follows even though the marginal benefit on the alternative-use value is not large enough to increase the seller's investment from the least costly level under spot transaction. The formal price contract has a negative value because of the increasing reneging temptation under repeated transaction. ${ }^{10}$

The two-investment example in section 2 corresponds to $\alpha=0$ (the buyer's takeit-or-leave-it offer), and hence the sign of $\Delta_{m}=m_{1}-m_{0}$ is the same as that of $p_{1}-p_{0}$ : Whether or not the alternative-use value is increasing or decreasing fully determines the value of writing a formal contract. In more general settings analyzed here, not only the marginal effect of investment on the alternative-use value but also the marginal effect on the value for the buyer matters.

We have so far developed intuition under assumption (13) so that $a^{o}=a_{0}$, in order to clarify how crucial the marginal effect of investment on the renegotiation price, and in particular the alternative-use value, is for the value of writing a formal price contract. Now consider a more general case of $a^{o}=a_{k} \geq a_{0}$. Suppose the investment incentive through renegotiation is so strong that the seller is induced to choose an investment higher than the least costly level even under spot transaction $\left(a_{k}>a_{0}\right)$. This advantage of not writing a formal price contract under spot transaction plays an additional beneficial role of reducing the reneging temptation under repeated transaction, because the incentive necessary to induce the seller to choose $a_{j}$ decreases from $a_{j}-a_{0}$ to $a_{j}-a_{k}$. The condition for writing a formal price contract to be valuable is now $\left(a_{k}-a_{0}\right)+\left(p_{j}-p_{k}\right)<0$ : The value of writing a formal contract thus may not be positive even if the renegotiation price is decreasing $\left(p_{j}<p_{k}\right)$.

However, writing a formal price contract can still be beneficial if the positive effect of eliminating the negative "market incentive" dominates the negative effect

\footnotetext{
${ }^{10}$ This result has a flavor of endogenous incomplete contract. Bernheim and Whinston (1998) show that parties may optimally leave some verifiable aspects of performance unspecified ("strategic ambiguity") in order to alter the set of feasible self-enforcing informal agreements. Not writing a formal contract in our model may be classified as one form of strategic ambiguity, although the underlying models and logics are different. While we model the dynamic contracting problem in the context of infinitely repeated interaction and emphasize the effect on the alternative-use values, they consider two-period dynamic models with or without intertemporal payoff linkages.
} 
of providing a larger incentive for the seller. We show such a case in the following example.

Example In this example, there are three feasible investments $a_{0}, a_{1}, a_{2}$ with $a_{0}=$ $0, a_{1}=\Delta_{a}>0$, and $a_{2}=2 \Delta_{a}$ : The investment cost increases linearly. Furthermore, $\Delta_{v} \equiv v_{2}-v_{1}=v_{1}-v_{0}>\Delta_{a}$, so that the value of the product for the buyer increases linearly as well. The inequality implies that the efficient investment is $a^{*}=a_{2}$. As for the alternative-use values, we assume $m_{0}<m_{1}>m_{2}$ satisfying $p_{1}-p_{0}>\Delta_{a}$ and $-\left(p_{2}-p_{1}\right)>\Delta_{a}$. The seller then chooses $a^{o}=a_{1}$ under spot transaction without a formal price contract.

Consider the implementation of $a^{*}=a_{2}$. Conditions (DE-NC) and (DE-FP) are rewritten as (14) and (15), respectively:

$$
\begin{aligned}
\Delta_{a}-\left(p_{2}-p_{1}\right) & \leq \frac{\delta}{1-\delta}\left(\pi_{2}-\pi^{o}\right) \\
2 \Delta_{a} & \leq \frac{\delta}{1-\delta}\left(\pi_{2}-\pi^{o}\right)
\end{aligned}
$$

Since $\Delta_{a}<p_{1}-p_{2}$, the left-hand side of (15) is smaller than that of (14). That is, writing a fixed-price contract is valuable under repeated transaction, despite a strictly negative value under spot transaction.

\section{Discussions}

\subsection{Other Forms of Formal Contracts}

We have so far restricted formal contracts to fixed-price contracts. This restriction is justified by our objective to show that writing a simple formal contract can help mitigate the holdup problem under repeated transaction while it does not under spot transaction (Proposition 4 (a)). However, we have also shown in Proposition 4 (b) that not writing a formal price contract but entirely relying on an informal agreement is desirable under some conditions. One may wonder whether this claim holds for more sophisticated formal contracts. In this subsection we study two well-studied forms of contracts and argue that they have no value under repeated transaction. 
First, consider a formal contract that specifies an option for the buyer to purchase the product at a prespecified price $p$. It is well known that under spot transaction, such an option contract resolves the holdup problem if the parties could commit not to renegotiate. In our model with $a^{*}=a_{j}$ and $a^{o}=a_{k}$, setting price $p^{*}=v_{j}$ does the job. To see this, first note that observing investment $a_{i}$, the buyer exercises the option and obtains payoff $v_{i}-p^{*}$ if $a_{i} \geq a_{j}$, and reject the product (payoff zero) if $a_{i}<a_{j}$. Expecting this response, the seller prefers to choose $a_{j}$ and obtain payoff $p^{*}-a_{j}$ than to choose $a_{i}<a_{j}$ with payoff $m_{i}-a_{i}$. However, since they cannot commit not to renegotiate, the buyer does not exercise the option and instead settles with the renegotiation price $p_{i}$ if $p^{*}>p_{i}$. The seller therefore chooses $a_{i}$ that maximizes $\min \left(p^{*}, p_{i}\right)-a_{i}$, which cannot attain the total surplus higher than $v_{k}-a_{k}$.

It is true that repeated interaction enables the parties to commit themselves not to renegotiate. However, the reneging temptation must be low enough to make such a commitment credible. And since reneging leads to renegotiation, the necessary and sufficient condition for $a_{j}$ to be implemented turns out to be the same as (DE-NC), the condition under no formal contract. Formal option contracts are hence no value even under repeated transaction.

As another well-studied contract, consider the following contract $\left(p^{1}, p^{0}\right)$, where $p^{1}$ is the price the buyer has to pay if she agrees to buy the product while $p^{0}$ is the price that she pays if she decides not to buy it (a liquidated damage measure). Again, this contract can resolve the holdup problem if no renegotiation is allowed. Since this contract is essentially equivalent to the option contract with $p^{1}-p^{0}$ being the option price, it is susceptible to renegotiation under spot transaction, and it has no value under repeated transaction.

The discussion clarifies the virtue of the fixed-price contract. The parties cannot reach an agreement in renegotiation, and hence it can eliminate the effects of renegotiation on the reneging temptation. More sophisticated contracts studied above open the door to renegotiation, and hence are of no value under spot transaction or repeated transaction. 


\subsection{Vertical Integration}

So far we are implicit about whether the transaction is within or between firms. We now extend the analysis to distinguish between nonintegration and integration, and show that writing a formal price contract without integration can be valuable under repeated transaction. Suppose there is an asset. The seller needs to use the asset to produce the product. We consider two cases. (i) The seller owns the asset. In this case the seller and the buyer are not integrated, and we call this case "outsourcing." (ii) The buyer owns the asset. In this case the seller and the buyer are integrated and the seller is just an employee of the buyer. We call this case "employment." These terms follow Baker et al. (2002). The owner of the asset has the residual right of control over the asset. Under outsourcing, the seller can thus use the asset freely, whether or not he actually trades with the buyer. Under employment, however, the buyer can exclude the seller from the use of the asset.

Our previous analysis corresponds to outsourcing, and the seller can realize the alternative-use value $m_{i}$ by using the asset to produce the product in an outside market. Under employment, the seller cannot use the asset when he does not trade with the buyer, and hence we assume that the disagreement payoff to the seller as well as to the buyer is zero. However, following the standard literature of the property rights approach (Grossman and Hart, 1986; Hart and Moore, 1990; Hart, 1995), we assume that ownership only affects the payoffs at the threat point, while the bargaining power is invariant. ${ }^{11}$

To simplify the analysis, we use our three-investment example in subsection 4.4

\footnotetext{
${ }^{11}$ Baker et al. (2002) assume that under employment, the buyer has all the bargaining power and can take the product without paying anything to the seller. It is hard to justify this assumption as long as investment affects the seller's human capital. If we instead adopt their assumption, our fixed-price contract turns out to be equivalent to their employment case. A related remark is found in a footnote of their paper (footnote 6, p.44) where they argue, thanking a referee for pointing it out, that employment "corresponds to a specific-performance contract that requires the upstream party to deliver the good to the downstream party". This remark is obscure and misleading, however. As our analysis shows, it is not only the duty of the upstream party to deliver the good but the duty of the downstream party to pay the specified price that has an important effect on the holdup problem.
} 
with some modification. We assume, as before, $\Delta_{v}=v_{2}-v_{1}=v_{1}-v_{0}$. We however alter the assumptions on the investment costs and the alternative-use values as follows: $\Delta_{a}=a_{2}-a_{1}>a_{1}-a_{0}=a_{1}>0$ ("convexity" of the cost function) and $\Delta_{m}=m_{2}-m_{1}=m_{1}-m_{0}$. We allow $\Delta_{m}$ to be either positive or negative, but we assume $\Delta_{v}>\Delta_{m}$. We also assume $\Delta_{v}>\Delta_{a}$ so that $a^{*}=a_{2}$.

First consider spot transaction. We assume $2\left(\alpha \Delta_{v}+(1-\alpha) \Delta_{m}\right)<a_{2}$, which implies that under our "spot outsourcing" without a formal contract, the seller prefers both $a_{0}$ and $a_{1}$ to $a_{2}$, and hence the holdup problem arises. The optimal investment for the seller, $a^{o}$, is given as follows:

$$
a^{o}= \begin{cases}a_{1} & \text { if } \alpha \Delta_{v}+(1-\alpha) \Delta_{m} \geq a_{1} \\ a_{0} & \text { if } \alpha \Delta_{v}+(1-\alpha) \Delta_{m}<a_{1}\end{cases}
$$

Under "spot employment," the renegotiated price after investment $a_{i}$ is $r_{i}=\alpha v_{i}$. We assume that there is underinvestment in spot employment as well. The following condition is sufficient.

$$
2 \alpha \Delta_{v}<a_{2}
$$

The optimal investment for the seller, denoted by $a^{e}$, is given as follows:

$$
a^{e}= \begin{cases}a_{1} & \text { if } \alpha \Delta_{v} \geq a_{1} \\ a_{0} & \text { if } \alpha \Delta_{v}<a_{1}\end{cases}
$$

If $a^{e}=a_{i}$, define the seller's payoff, the buyer's payoff, and the joint value, respectively, as follows:

$$
\pi_{S}^{e}=w+r_{i}-a_{i}, \quad \pi_{B}^{e}=v_{i}-w-r_{i}, \quad \pi^{e}=v_{i}-a_{i}
$$

The comparison of spot employment with spot outsourcing is simple. If the "market incentive" is positive $\left(\Delta_{m}>0\right), a^{o} \geq a^{e}$, while $a^{o} \leq a^{e}$ if the market incentive is negative. Spot employment eliminates the effect of the alternative-use value on the renegotiated price. It is optimal if and only if the market incentive attenuates the seller's incentive to invest.

Next we analyze repeated transaction. Employment under repeated transaction is called "relational employment." The major issue here is whether ownership can be 
renegotiated after either party reneges on the relational contract. Baker et al. (2002) assume that renegotiation costs are low enough to allow the parties to negotiate over asset ownership. Under their assumption, the seller and the buyer thus choose the optimal spot ownership structure, either spot outsourcing (if $\Delta_{m}>0$ ) or spot employment (if $\Delta_{m}<0$ ) after reneging, and maintain that form forever. Halonen (2002) introduces renegotiation costs explicitly, and consider the other polar case in which costs are so high that the ownership structure will not be renegotiated.

If renegotiation over asset ownership is feasible, it turns out that the comparison between relational outsourcing with no formal contract and relational employment is the same as that between spot outsourcing and spot employment. That is, relational employment is optimal if and only if $\Delta_{m}<0$. And noting that $\Delta_{m}<0$ is a necessary condition for a formal price contract to dominate the no contract case in our model, we can conclude that writing a formal price contract under relational outsourcing is never optimal because relational employment can provide stronger investment incentives for the seller through renegotiation.

In the rest of this subsection, we hence focus on the second case in which renegotiation over asset ownership is infeasible. Condition (DE-NC) for relational outsourcing with no formal contract is rewritten as follows:

$$
\begin{array}{ll}
a_{2}-2\left(\alpha \Delta_{v}+(1-\alpha) \Delta_{m}\right) \leq \frac{\delta}{1-\delta}\left(\pi_{2}-\pi_{0}\right) & \text { if } \alpha \Delta_{v}+(1-\alpha) \Delta_{m}<a_{1} \\
\Delta_{a}-\left(\alpha \Delta_{v}+(1-\alpha) \Delta_{m}\right) \leq \frac{\delta}{1-\delta}\left(\pi_{2}-\pi_{1}\right) & \text { if } \alpha \Delta_{v}+(1-\alpha) \Delta_{m} \geq a_{1}
\end{array}
$$

The corresponding condition for relational outsourcing with a formal price contract is given as follows:

$$
\begin{array}{ll}
a_{2} \leq \frac{\delta}{1-\delta}\left(\pi_{2}-\pi_{0}\right) & \text { if } \alpha \Delta_{v}+(1-\alpha) \Delta_{m}<a_{1} \\
a_{2} \leq \frac{\delta}{1-\delta}\left(\pi_{2}-\pi_{1}\right) & \text { if } \alpha \Delta_{v}+(1-\alpha) \Delta_{m} \geq a_{1}
\end{array}
$$

Finally, the necessary and sufficient condition for $a_{2}$ to be implemented under relational employment can be derived similarly and is given as follows:

$$
\begin{array}{ll}
a_{2}-2 \alpha \Delta_{v} \leq \frac{\delta}{1-\delta}\left(\pi_{2}-\pi_{0}\right) & \text { if } \alpha \Delta_{v}<a_{1} \\
\Delta_{a}-\alpha \Delta_{v} \leq \frac{\delta}{1-\delta}\left(\pi_{2}-\pi_{1}\right) & \text { if } \alpha \Delta_{v} \geq a_{1}
\end{array}
$$


Now suppose $\Delta_{m}<0$. If $\alpha \Delta_{v} \geq a_{1}-(1-\alpha) \Delta_{m}$ so that $a^{o}=a^{e}=a_{1}$, or if $\alpha \Delta_{v}<a_{1}$ so that $a^{o}=a^{e}=a_{0}$, then the future loss from reneging is the same under relational outsourcing with no formal contract, relational outsourcing with a fixed-price contract, or relational employment. And hence relational employment (integration) is optimal. However, if $a_{1} \leq \alpha \Delta_{v}<a_{1}-(1-\alpha) \Delta_{m}$ so that $a^{o}=$ $a_{0}<a_{1}=a^{e}$, the comparison is involved. In this case, we have to compare among (16), (18), and (21). Under relational outsourcing with or without a formal contract, the future per period loss is $\pi_{2}-\pi_{0}$, which is larger than $\pi_{2}-\pi_{1}$, the future per period loss under relational employment. However, the left-hand side of (16) and that of (18) are also larger than that of (21). We can thus show that depending on parameter values, either form can be optimal, in particular, relational outsourcing with a formal price contract can be optimal, even though integration is allowed.

\section{Concluding Remarks}

This paper has offered a new perspective on the role of formal contracts in resolving the holdup problem. In situations where formal contracts have no value under spot transaction due to the cooperative nature of the relation-specific investment, we have shown that writing a simple fixed-price contract can be valuable under repeated transactions. In our model, there is a range of parameter values in which a formal price contract combined with a relational contract can help mitigate the holdup problem, while under another parameter range not writing a formal contract but entirely relying on a relational contract increases the total surplus of the buyer and the seller. The key factor in distinguishing between these two cases is how the investment affects the alternative-use value.

Our analysis may shed a new light on recent empirical investigations on the relationship between relational governance and formal contracts. In the empirical literature in transaction cost economics, the majority of previous researches have studied how several transactional properties (representing asset specificity, uncertainty and transactional frequency) affect organizational mode conceptualized by market, hierarchy, or various hybrid and intermediate modes (see e.g. Shelanski and Klein (1995) and Boerner and Macher (2002) for surveys). 
As an important contribution to this literature, recently several researchers have investigated the relationship between relational governance and formal contracts (see e.g. Banerjee and Duflo (2000); Poppo and Zenger (2002); Kalnins and Mayer (2004)). Poppo and Zenger (2002) found in their investigation of informational service outsourcing that, controlling for several transactional properties such as asset specificity, increases in the level of relational governance were associated with greater levels of complexity in formal contracts (see Ryall and Sampson (2003) for a related finding). Their finding can be regarded as broadly consistent with our theoretical prediction for the case in which the relation-specific investment decreases the alternative-use value: in such a case formal contracts can play an important role under repeated transactions. Our model identifies the distinction of whether the alternative-use value is increasing or decreasing in investment as an important factor to determine the value of formal contracts. It yields a previously unexplored testable implication that formal contracts and relational governance can function as complements when the alternative-use value is decreasing in investment (which can be interpreted as a higher level of asset specificity), while they can function as substitutes otherwise.

\section{References}

Asanuma, Banri, "Manufacturer-Supplier Relationships in Japan and the Concept of Relation-Specific Skill," Journal of the Japanese and International Economies, 1989, 3, 1-30.

Baker, George, Robert Gibbons, and Kevin J. Murphy, "Subjective Performance Measures in Optimal Incentive Contracts," Quarterly Journal of Economics, 1994, 109 (2), 1125-1156.

_ , _ and _ , "Bringing the Market Inside the Firm?," American Economic Review Papers and Proceedings, May 2001, 91 (2), 212-218.

_, _, and _ , "Relational Contracts and the Theory of the Firm," Quarterly Journal of Economics, 2002, 117, 39-84. 
Banerjee, Abhijit V. and Esther Duflo, "Reputation Effects and the Limits of Contracting: A Study of the Indian Software Industry," Quarterly Journal of Economics, 2000, 115, 989-1017.

Bernheim, B. Douglas and Michael D. Whinston, "Incomplete Contracts and Strategic Ambiguity," American Economic Review, 1998, 88, 902-932.

Boerner, Christopher S. and Jeffrey T. Macher, "Transaction Cost Economics: An Assessment of Empirical Research in the Social Sciences," 2002. mimeo.

Cai, Hongbin, "A Theory of Joint Asset Ownership," Rand Journal of Economics, 2003, 34, 63-77.

Che, Yeon-Koo and Donald B. Hausch, "Cooperative Investments and the Value of Contracting," American Economic Review, 1999, 89, 125-147.

- and József Sákovics, "A Dynamic Theory of Holdup," Econometrica, 2004, 72, 1063-1103.

Coase, Ronald H., "The Nature of the Firm: Influence," Journal of Law, Economics, and Organization, 1988, 4, 33-47.

_ , "The Acquisition of Fisher Body by General Motors," Journal of Law and Economics, 2000, 43, 15-31.

Edlin, Aaron S. and Stefan Reichelstein, "Holdups, Standard Breach Remedies, and Optimal Investment," American Economic Review, 1996, 86, 478-501.

Grossman, Sanford J. and Oliver D. Hart, "The Costs and Benefits of Ownership: A Theory of Vertical and Lateral Integration," Journal of Political Economy, 1986, 94, 691-719.

Gul, Faruk, "Unobservable Investment and the Hold-Up Problem," Econometrica, 2001, 69, 343-376.

Halonen, Maija, "Reputation and the Allocation of Ownership," The Economic Journal, 2002, 112, 539-558. 
Hart, Oliver, Firms, Contracts, and Financial Structure, Oxford: Oxford University Press, 1995.

_ and John Moore, "Property Rights and the Nature of the Firm," Journal of Political Economy, 1990, 98, 1119-58.

Holmström, Bengt and John Roberts, "The Boundaries of the Firm Revisited," Journal of Economic Perspectives, 1998, 12, 73-94.

Kalnins, Arturs and Kyle J. Mayer, "Relationships and Hybrid Contracts: An Analysis of Contract Choice in Information Technology," Journal of Law, Economics, and Organization, 2004, 20, 207-229.

Klein, Benjamin, Robert Crawford, and Armen Alchian, "Vertical Integration, Appropriable Rents, and the Competitive Contracting Process," Journal of Law and Economics, 1978, 21, 297-326.

Levin, Jonathan, "Relational Incentive Contracts," American Economic Review, June 2003, 93 (3), 835-847.

Morita, Hodaka, "Partial Ownership Induces Customised Investments under Repeated Interaction: An Explanation of Japanese Manufacturer-Suppliers Relationships," Scottish Journal of Political Economy, 2001, 48, 345-359.

Pitchford, Rohan and Christopher M. Snyder, "A Solution to the Hold-Up Problem Involving Gradual Investment," Journal of Economic Theory, 2004, 114, 88-103.

Poppo, Laura. and Todd Zenger, "Do Formal Contracts and Relational Governance Function as Substitutes or Complements?," Strategic Management Journal, 2002, 23, 707-725.

Rajan, Raghuram G. and Luigi Zingales, "Power in a Theory of the Firm," Quarterly Journal of Economics, 1998, 113, 387-432.

Ryall, Michael and Rachelle Sampson, "Do Prior Alliances Influence Contract Structure? Evidence from Technology Alliance Contracts," 2003. mimeo. 
Schmidt, Klaus M. and Monika Schnitzer, "The Interaction of Explicit and Implicit Contracts," Economics Letters, 1995, 48, 193-199.

Shelanski, Howard and Peter Klein, "Empirical Research in Transaction Cost Economics: A Review and Assessment," Journal of Law, Economics, and Organization, 1995, 11, 335-361.

Williamson, Oliver E., The Economic Institutions of Capitalism: Firms, Markets, Relational Contracting, New York: The Free Press, 1985. 